\title{
Eficiência da água no combate aos incêndios florestais
}

Questões econômicas e culturais, fazem com que grande parte dos combates aos incêndios florestais no Brasil ainda sejam baseados na aplicação da água como único recurso. Porém, a escassez desse recurso nas proximidades das ocorrências aliada à problemática dos períodos de estiagem e mudanças climáticas, torna necessário o uso estratégico desse recurso. Desse modo, com o presente estudo, objetivou-se a realização da análise do efeito de diferentes volumes de água no combate aos incêndios em florestas de produção. $O$ experimento foi realizado em plantios de eucalipto com 7 anos de idade, em uma propriedade rural no município de São José do Calçado, sul do estado do Espírito Santo. O material combustível utilizado foi serapilheira seca depositada no solo de forma natural, constituída de folhas secas e galhos de até $5 \mathrm{~cm}$ de diâmetro. A área experimental foi composta por 18 parcelas, com dimensões de $1 \mathrm{~m} \times 3 \mathrm{~m}$. Foram utilizados diferentes volumes de água por metro quadrado em cada tratamento, $0,5 \mathrm{~L} ; 1 \mathrm{~L} ; 1,5 \mathrm{~L} ; 2 \mathrm{~L} ; 2,5 \mathrm{~L}$ e testemunha sem água. Antes de iniciar o processo de ignição, aplicaram-se os devidos tratamentos de forma homogênea no espaço de $1 \mathrm{~m} 2$ designado para aplicação. No total, foram cinco tratamentos com três repetições cada e um tratamento testemunha, sem adição de água. No estudo foram avaliados, a altura de chamas, a velocidade do vento, tempo e intensidade de queima. A eficiência da água foi comprovada em todos os volumes testados, apresentando aumento no tempo de queima e reduções na altura das chamas e na intensidade de queima relativamente significativos. 0 tratamento 4 foi o mais adequado e indicado, sendo o mais viável ambientalmente e economicamente. Existe uma relação diretamente proporcional entre a altura das chamas e a intensidade de queima e inversamente proporcional entre os volumes de água aplicados e a altura de chama e intensidade de queima.

Palavras-chave: Proteção florestal; Intensidade de queima; Técnicas e operações florestais.

\section{Water efficiency in fighting forest fire}

Economic and cultural issues, make the great part of combating forest fires in Brazil still based on the application of water as the only resource. However, the scarcity of this resource in the vicinity of the occurrences combined with the problem of periods of drought and climate change, makes it necessary the strategic use of this resource. Thus, this study aimed to analyze the effect of different volumes of water in fighting fires in production forests. The experiment was carried out on 7-year-old eucalyptus plantations, on a rural property in the municipality of São José do Calçado, south of the state of Espírito Santo. The combustible material used was dry litter deposited in the soil in a natural way, consisting of dry leaves and branches up to $5 \mathrm{~cm}$ in diameter. The experimental area was composed of 18 plots, with dimensions of $1 \mathrm{~m} \mathrm{x} 3 \mathrm{~m}$. Different volumes of water per square meter were used in each treatment, $0.5 \mathrm{~L} ; 1 \mathrm{~L} ; 1.5 \mathrm{~L} ; 2 \mathrm{~L} ; 2.5 \mathrm{~L}$ and contro without water. Before starting the ignition process, the appropriate treatments were applied homogeneously in the space of $1 \mathrm{~m} 2$ designated for application. In total, there were five treatments with three repetitions each and a control treatment, without adding water. In the study, the height of flames, wind speed, time and intensity of burning were evaluated. The water efficiency was proven in all volumes tested, showing a significant increase in the burning time and reductions in the height of the flames and in the burning intensity. Treatment 4 was the most appropriate and indicated, being the most environmentally and economically viable. There is a directly proportional relationship between the height of the flames and the burning intensity and inversely proportional between the volumes of water applied and the flame height and burning intensity.

Keywords: Forest protection; Intensity of burning; Techniques and forestry operations.

Topic: Ciências Florestais

Reviewed anonymously in the process of blind peer.
Received: 03/02/2021

Approved: $27 / 02 / 2021$
Sillas Ramos Mariano (iD

Universidade Federal do Espírito Santo, Brasil http://lattes.cnpq.br/5019454567940256

http://orcid.org/0000-0002-9830-3434

marianosillas@gmail.com

Nilton Cesar Fiedler (iD)

Universidade Federal do Espírito Santo, Brasil

http://lattes.cnpq.br/8699171075880935

http://orcid.org/0000-0002-3895-661X

niltoncesarfiedler@yahoo.com.br

\section{Weslen Pintor Canzian (iD}

Universidade Federal do Espírito Santo, Brasil

http://lattes.cnpq.br/7543156387534740

http://orcid.org/0000-0003-0847-4692

weslenpcanzian@hotmail.com

\author{
Elaine Cristina Gomes da Silva (DD \\ Universidade Federal do Espírito Santo, Brasil \\ http://lattes.cnpq.br/1675286065721578 \\ http://orcid.org/0000-0003-4214-2042 \\ ecristinags@gmail.com \\ Saulo Boldrini Gonçalves (ic) \\ Universidade Estadual do Centro-Oeste, Brasil \\ http://lattes.cnpq.br/2901108215732199 \\ http://orcid.org/0000-0001-6352-3413 \\ sauloboldrinig@hotmail.com \\ Antonio Henrique Cordeiro Ramalho (iD) \\ Universidade Federal do Espírito Santo, Brasil \\ http://lattes.cnpq.br/7064955262943008 \\ http://orcid.org/0000-0002-0037-5422 \\ henriquecr2012@hotmail.com
}

\section{Referencing this:}

MARIANO, S. R.; FIEDLER, N. C.; CANZIAN, W. P.; SILVA, E. C. G.; GONÇALVES, S. B.; RAMALHO, A. H. C.. Eficiência da água no combate aos incêndios florestais. Revista Ibero Americana de Ciências Ambientais, v.12, n.2, p.77-85, 2021. DOI:

http://doi.org/10.6008/CBPC2179-6858.2021.002.0009 


\section{INTRODUÇÃO}

No atual cenário do setor florestal, os incêndios caracterizam-se como a principal ameaça aos interesses econômicos, sociais e ambientais das empresas e áreas protegidas, além de contribuírem significativamente para as mudanças climáticas (SOUZA et al., 2012; FIEDLER et al., 2020). Diversos autores, como Souza et al. (2012), Barbero et al. (2015), Syphard et al. (2017) e Canzian et al. (2018), definem os incêndios florestais como um dos mais custosos e prejudiciais desastres ambientais do Brasil.

Dado o fato que, Fiedler et al. (2020) conceituam os incêndios florestais como todo fogo sem controle que consome material combustível vegetal, se estendendo para benfeitorias, máquinas e equipamentos agrícolas e/ou florestais e áreas residenciais. A aplicação de técnicas e planejamentos embasados em conhecimentos práticos e científicos, configuram-se em potenciais aliados na redução dos danos causados por esses sinistros. No entanto, a carência de informações que auxiliem na tomada de decisão quanto à escolha dessas técnicas, interfere negativamente no direcionamento de recursos (SANT'ANNA et al., 2007), culminando em dois possíveis cenários: investimentos acima do necessário em proteção ou investimentos insuficientes, colocando a segurança das florestas em risco (RODRÍGUEZ et al., 2013)

Desta forma, mesmo que o cenário de informações seja limitado, o alto potencial destrutivo dos incêndios em florestas de produção exige que sejam estabelecidas estratégias de prevenção e combate inovadoras. Em geral, o combate de incêndios florestais ocorre através da aplicação de água com ou sem a adição de produtos que potencializam seus efeitos na eliminação do fogo. Canzian et al. (2018) destacam os efeitos benéficos da utilização de produtos químicos com potencial retardante de fogo aliados à água no combate aos incêndios florestais. No entanto, tais produtos, por serem em sua maioria advindos de importações, possuem custo relativamente alto.

Tanto o empecilho econômico quanto as questões culturais, fazem com que grande parte dos combates aos incêndios florestais no Brasil ainda sejam baseados na aplicação da água como único recurso. Porém, Canzian et al. (2018) e Fiedler et al. (2020) elucidam a dificuldade de disponibilidade de água nas proximidades das ocorrências dos incêndios florestais aliada à problemática dos períodos de estiagem que se tem agravado em todo o planeta, dada as mudanças climáticas, tornando necessário o uso estratégico desse recurso.

Assim, com o presente estudo, objetivou-se a realização da análise do efeito de diferentes volumes de água no combate aos incêndios em florestas de produção. A hipótese que norteou a pesquisa foi de que volumes mais altos de água culminariam em maiores índices de eficiência no combate aos incêndios florestais. A justificativa da realização de tal pesquisa permeia sobre a importância do combate eficiente dos incêndios florestais bem como da determinação de técnicas de eliminação do fogo por meio de volumes reduzidos de água. 


\section{MATERIAIS E MÉTODOS}

\section{Descrição da área de estudo}

O experimento foi realizado em plantios de eucalipto com 7 anos de idade, em uma propriedade rural no município de São José do Calçado, sul do estado do Espírito Santo ( $20^{\circ} 55^{\prime} 55^{\prime \prime} \mathrm{S}$ e $41^{\circ} 37^{\prime} 34^{\prime \prime}$ W) (Figura 1).

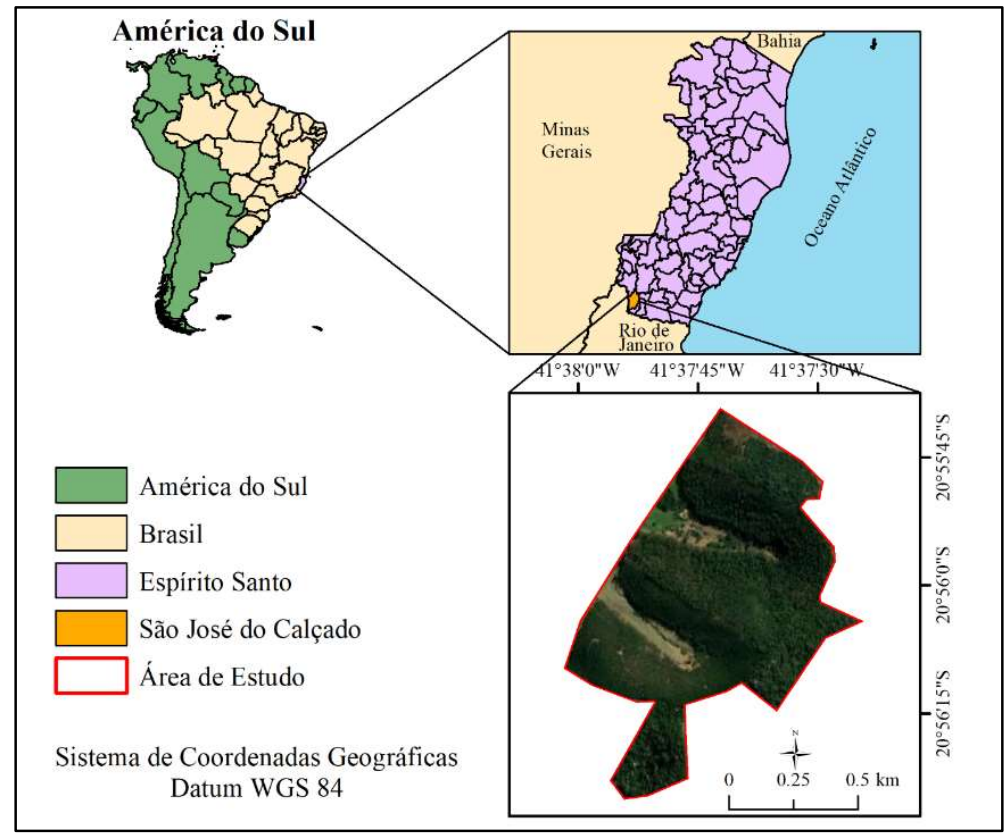

Figura 1: Mapa de localização da área de estudo.

De acordo com o sistema de classificação climática de Köppen, a região é caracterizada por ser do tipo $\mathrm{Cfb}$, com verão curto e fresco. A altitude é de 560 metros, temperatura média anual do ar varia entre 18 ㅇ e 20 ㄷ e precipitação média entre 1.000 a 1.300 mm (ALVARES et al., 2013).

\section{Material combustível utilizado}

O material combustível utilizado é característico de plantio de eucalipto, ou seja, a serapilheira seca depositada no solo de forma natural, constituída de folhas secas e galhos de até $5 \mathrm{~cm}$ de diâmetro.

\section{Procedimento de amostragem}

A área experimental foi composta por 18 parcelas, com dimensões de $1 \mathrm{~m} \times 3 \mathrm{~m}$ (Figura 2A e 2B). Após a elaboração e montagem das parcelas, procedeu-se com a escolha aleatória do tratamento que cada uma receberia. Assim, antes de iniciar o processo de ignição, aplicaram-se os devidos tratamentos de forma homogênea no espaço de $1 \mathrm{~m} 2$ designado para aplicação (Figura 3).

No total, foram cinco tratamentos com três repetições cada e um tratamento testemunha, sem adição de água (Tabela 1).

Após a aplicação dos tratamentos, foi dada a ignição no material combustível na de forma que as chamas seguissem o sentido de propagação até chegarem à área submetida aos tratamentos. A primeira parte das leiras (sem aplicação do tratamento) serviu apenas para linha de fogo se estabelecer. As análises 
foram realizadas apenas na extensão que com aplicação do tratamento.

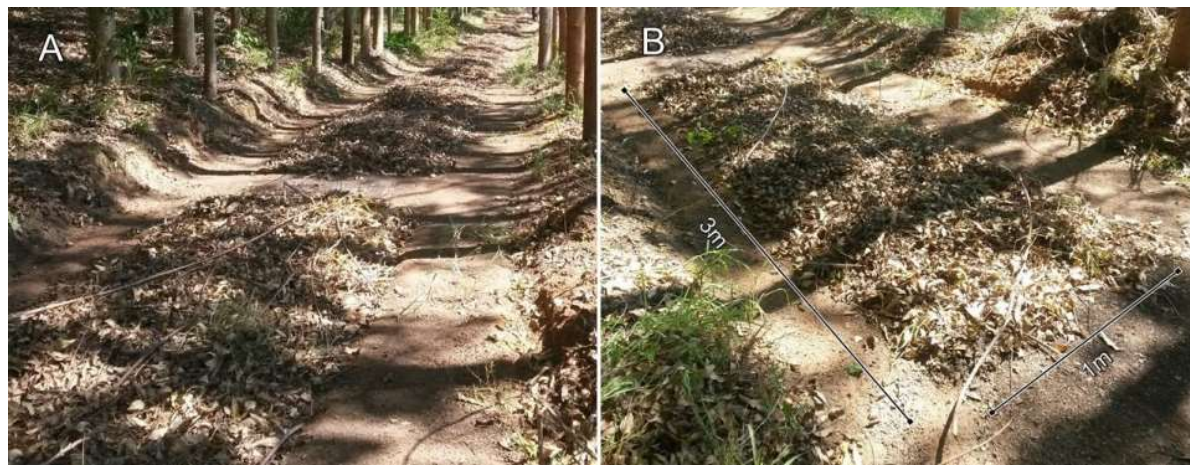

Figura 2: A) Disposição das parcelas; B) Dimensões da parcela.

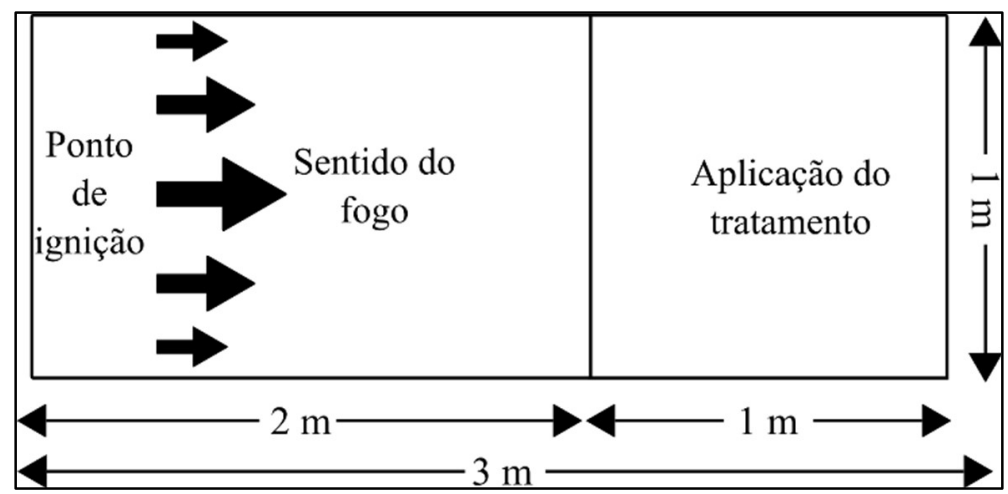

Figura 3: Esquema de aplicação dos tratamentos.

Tabela 1: Tratamentos analisados de acordo com o volume de água, em litros, aplicado.

\begin{tabular}{lll}
\hline Tratamentos & Volume de água $(L)$ & Repetições \\
\hline Testemunha & 0 & 3 \\
T1 & 0,5 & 3 \\
T2 & 1,0 & 3 \\
T3 & 1,5 & 3 \\
T4 & 2,0 & 3 \\
T5 & 2,5 & 3 \\
\hline Total & - & 18 \\
\hline
\end{tabular}

\section{Parâmetros de caracterização do fogo avaliados}

Durante a queima de cada parcela foram realizadas as avaliados os seguintes parâmetros: Altura de chamas: avaliada com auxílio de gabaritos graduados; Velocidade do vento: coletada com auxílio de anemômetro; Tempo de queima sem tratamento: tempo gasto para o fogo queimar as parcelas sem água; Tempo de queima com tratamento: tempo gasto para o fogo queimar o material combustível submetido à aplicação dos tratamentos com água; e Intensidade de queima: taxa de calor liberada por unidade de tempo e de comprimento da frente de fogo (SANT'ANNA et al., 2020). Para analisar o efeito dos distintos volumes de água na contenção do fogo, foi calculada a intensidade de queima pela equação de Byram (1959), conforme Equação 1.

$$
\mathrm{I}=\mathrm{H} \cdot \mathrm{w} \cdot \mathrm{r} \quad \text { (Eq. 1) }
$$

Onde, o l é a intensidade de queima $\left(\mathrm{kcal} \mathrm{m}^{-1} \mathrm{~s}^{-1}\right)$, o $\mathrm{H}$ é o poder calorífico do material combustível dominante ( $\mathrm{kcal} \mathrm{kg}$ $\left.{ }^{1}\right)$, o w é a carga de material combustível disponível $\mathrm{kg} \mathrm{m}^{-2} \mathrm{e}$ o r é a velocidade de propagação do fogo $\left(\mathrm{m} \mathrm{s}^{-1}\right)$.

A umidade do material combustível foi determinada tendo como base três repetições de uma 
amostra de $1 \mathrm{~m}^{2}$, retirada da leira única que foi montada para a realização das queimas. Essas amostras de material foram levadas para estufa a $65 \stackrel{\circ}{ } \mathrm{C}$ e mantida até o peso se manter constante. Após esse procedimento, foi quantificada a matéria seca e a umidade. Em seguida o poder calorífico foi determinado através de cinco amostras de igual peso $(0,5 \mathrm{~g})$ em uma bomba calorimétrica.

A intensidade de queima é uma variável mundialmente utilizada para caracterização do comportamento do fogo e está diretamente associada à reação da combustão. Por ter relação direta com a velocidade de propagação do fogo, espera-se que, quanto maior a velocidade de propagação do fogo, maior a quantidade de energia liberada para o ambiente e mais rápida a combustão do material.

\section{Análise estatística}

Para análise estatística dos valores de tempo e intensidade, o delineamento experimental aplicado foi DIC (delineamento inteiramente casualizado). Inicialmente foi aplicada a análise de variância (ANOVA), e posteriormente, para a comparação das médias, foi aplicado o teste de Tukey a 5\% de probabilidade de erro com auxílio do software Assistat 7.7. Utilizando o software Excel 2013, foi verificado, com base na regressão linear, se existia relação significativa entre as variáveis independentes (tratamentos com água) e as variáveis dependentes (tempos e intensidades de queima).

\section{RESULTADOS}

A Tabela 2 apresenta os valores médios e os respectivos desvios-padrão acerca da massa úmida e massa seca do material combustível, temperatura do ar durante a realização do estudo, umidade relativa e poder calorífico do material combustível. A Tabela 3 apresenta os valores relativos ao tempo de queima, em segundos, para cada um dos tratamentos.

Tabela 2: Valores médios da massa úmida e massa seca do material combustível, temperatura do ar, umidade e poder calorífico do material combustível.

\begin{tabular}{lllllll}
\hline $\begin{array}{l}\text { Massa úmida } \\
\left(\mathrm{kg} \mathrm{m}^{-2}\right)\end{array}$ & $\begin{array}{l}\text { Massa seca } \\
\left(\mathrm{kg} \mathrm{m}^{-2}\right)\end{array}$ & $\begin{array}{l}\text { Temperatura do ar } \\
(\text { o- })\end{array}$ & $\begin{array}{l}\text { Velocidade do vento } \\
\left(\mathrm{m} \mathrm{s}^{-1}\right)\end{array}$ & $\begin{array}{l}\text { Umidade do } \\
\text { combustível (\%) }\end{array}$ & material & $\begin{array}{l}\text { Poder calorífico } \\
(\mathrm{kcal})\end{array}$ \\
\hline $2,95 \pm 0,22$ & $2,5 \pm 0,17$ & $32,87 \pm 1,76$ & $2,02 \pm 0,02$ & $18,00 \pm 0,11$ & $5276,78 \pm 0,26$ \\
\hline
\end{tabular}

Tabela 3: Valores médios do tempo de queima em função dos tratamentos aplicados.

\begin{tabular}{lll}
\hline Tratamentos & Tempo de queima $(\mathrm{s})$ & Aumento (\%) \\
\hline Testemunha & $56,00 \mathrm{a}$ & - \\
T1 & $216,67 \mathrm{~b}$ & 286.91 \\
T2 & $374,67 \mathrm{c}$ & 569.05 \\
T3 & $444,33 \mathrm{~cd}$ & 693.45 \\
T4 & $581,33 \mathrm{~d}$ & 938,09 \\
T5 & $822,00 \mathrm{e}$ & 1367,86 \\
\hline
\end{tabular}

Onde: Testemunha $=0 \mathrm{~L}$ de água; $\mathrm{T} 1=0,5 \mathrm{~L}$ de água; $\mathrm{T} 2=1,0 \mathrm{~L}$ de água; $\mathrm{T} 3=1,5 \mathrm{~L}$ de água; $\mathrm{T} 4=2,0 \mathrm{~L}$ de água; $\mathrm{T} 5=2,5$ $\mathrm{L}$ de água. Médias seguidas de mesma letra, dentro da mesma coluna, não diferem estatisticamente ao nível de $5 \%$ de probabilidade pelo Teste de Tukey.

Na Tabela 4 observam-se os dados obtidos das médias de altura de chama, intensidade de fogo de cada tratamento analisado, porcentagem de redução na altura de chama e intensidade de queima. 
Tabela 4: Altura de chama e redução, intensidade de queima e redução.

\begin{tabular}{|c|c|c|c|c|}
\hline \multirow{2}{*}{ Tratamentos } & \multirow{2}{*}{ Altura de chama (m) } & \multirow{2}{*}{$\begin{array}{l}\text { Intensidade de queima } \\
\left(\mathrm{kcal} \mathrm{m}^{-1} \mathrm{~s}^{-1}\right)\end{array}$} & \multicolumn{2}{|l|}{ Redução (\%) } \\
\hline & & & Altura de chama & Intensidade de queima \\
\hline Testemunha & $1,43 \mathrm{a}$ & $287,90 \mathrm{a}$ & - & - \\
\hline $\mathrm{T} 1$ & $1,00 \mathrm{~b}$ & $72,00 \mathrm{~b}$ & 30,23 & 74,99 \\
\hline $\mathrm{T} 2$ & $0,70 \mathrm{bc}$ & $41,30 \mathrm{c}$ & 51,16 & 85,66 \\
\hline T3 & $0,47 \mathrm{~cd}$ & $34,63 \mathrm{c}$ & 67,44 & 87,97 \\
\hline T4 & $0,33 d$ & $26,45 \mathrm{~cd}$ & 76,74 & 90,81 \\
\hline T5 & $0,33 d$ & $18,78 d$ & 76,74 & 93,48 \\
\hline
\end{tabular}

Onde: Testemunha = $0 \mathrm{~L}$ de água; $\mathrm{T} 1=0,5 \mathrm{~L}$ de água; $\mathrm{T} 2=1,0 \mathrm{~L}$ de água; $\mathrm{T} 3=1,5 \mathrm{~L}$ de água; $\mathrm{T} 4=2,0 \mathrm{~L}$ de água; $\mathrm{T} 5=2,5$ $L$ de água. Médias seguidas de mesma letra, dentro da mesma coluna, não diferem estatisticamente ao nível de $5 \%$ de probabilidade pelo Teste de Tukey.

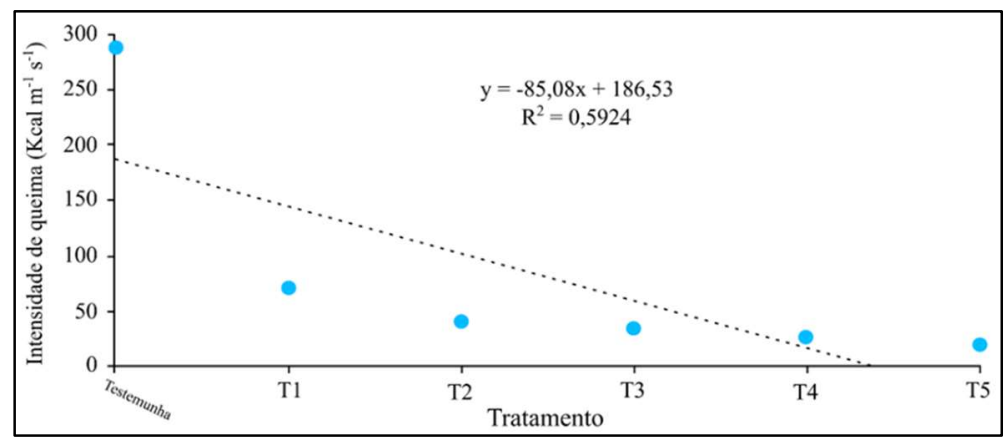

Figura 3: Regressão da intensidade de queima pelo volume de água por $\mathrm{m}^{2}$. Onde: Testemunha $=0 \mathrm{~L}$ de água; $\mathrm{T} 1=0,5$ $\mathrm{L}$ de água; $\mathrm{T} 2=1,0 \mathrm{~L}$ de água; $\mathrm{T} 3=1,5 \mathrm{~L}$ de água; $\mathrm{T} 4=2,0 \mathrm{~L}$ de água; $\mathrm{T} 5=2,5 \mathrm{~L}$ de água.

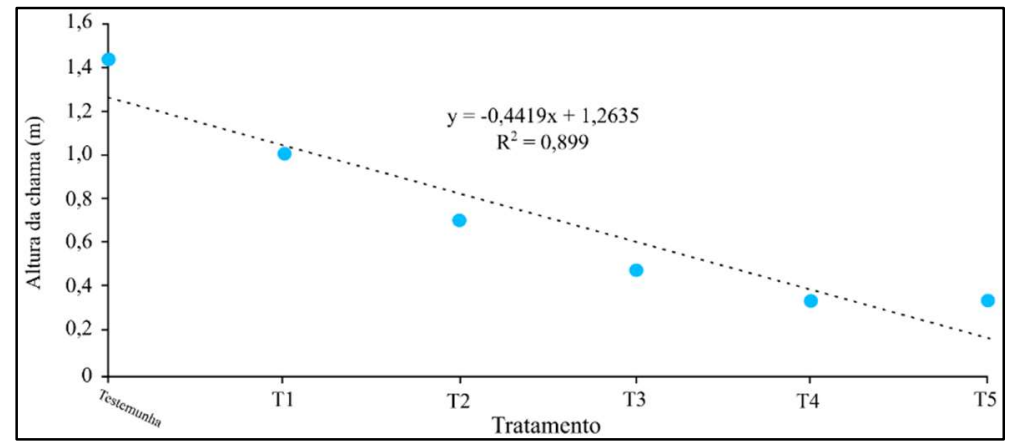

Figura 4: Regressão da altura de chama pelo volume de água por $m^{2}$. Onde: Testemunha $=0 \mathrm{~L}$ de água; $T 1=0,5 \mathrm{~L}$ de água; $\mathrm{T} 2=1,0 \mathrm{~L}$ de água; $\mathrm{T} 3=1,5 \mathrm{~L}$ de água; $\mathrm{T} 4=2,0 \mathrm{~L}$ de água; $\mathrm{T} 5=2,5 \mathrm{~L}$ de água.

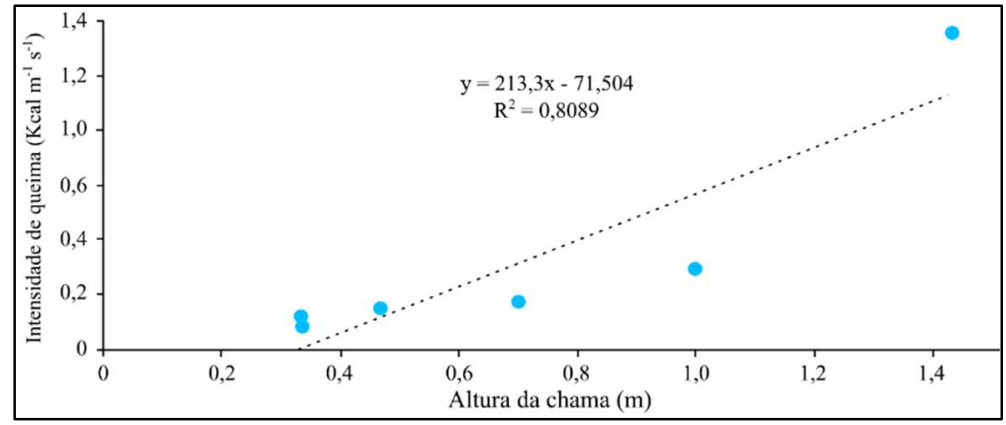

Figura 5: Regressão da intensidade de queima pela altura de chama.

Os dados de intensidade de queima, pelo teste de Tukey ao nível de $5 \%$ de probabilidade, inicialmente não apresentaram diferença significativa entre os tratamentos, resultando diferença apenas dos tratamentos com a testemunha. Desta forma, a análise estatística de intensidade de queima foi realizada apenas entre as médias dos tratamentos para verificar o efeito entre os diferentes volumes de água aplicados. Na Figura 3 está representado o gráfico de regressão da intensidade de queima em relação ao tratamento aplicado (volume de água). Na Figura 4 é observada a relação da altura de chama de acordo com 
tratamento. Depois de analisada a intensidade de queima e altura de chama em função do volume de água aplicado por tratamento, foi avaliado por meio de regressão a relação entre a intensidade de queima e a altura das chamas (Figura 5).

\section{DISCUSSÃO}

A densidade da manta de serapilheira desta pesquisa foi de $2,95 \mathrm{~kg} \mathrm{~m}^{-2}$, ou seja, $29,5 \mathrm{Mg} \mathrm{ha}^{-1}$ de galhos finos e folhas secas de eucalipto sobre o solo (Tabela 2). Esse valor é superior ao encontrado Maraboti et al. (2016) em sua análise de retardantes de fogo em florestas de eucalipto, onde encontrou uma manta de serapilheira de $25 \mathrm{Mg} \mathrm{ha}^{-1}$.

A massa seca do material combustível florestal utilizado na presente pesquisa $\left(2,5 \pm 0,17 \mathrm{~kg} \mathrm{~m}^{2}\right)$ (Tabela 2), se aproximou dos resultados encontrados por Souza et al. (2003), que ao analisar a quantidade de combustível da floresta de superfície em uma floresta de Eucalyptus dunii Maiden com 7 anos de idade, encontraram o valor de $2,22 \mathrm{~kg} \mathrm{~m}^{2}$. Fiedler et al. (2020), encontraram um valor inferior de massa seca (2,09 $\mathrm{Mg} \mathrm{ha}^{-1}$ ) tanto ao encontrado na presente pesquisa quanto ao encontrado por Souza et al. (2003). Essa diferença de massa seca pode ter relação com a idade do povoamento, características climáticas, método de secagem, entre outros.

Já a umidade do material (18\%) (Tabela 2), foi superior à encontrada por Canzian et al. (2016), que encontraram o valor de $14 \%$ de umidade e inferior à encontrada por Fiedler et al. (2020), que encontraram o valor de $19,61 \%$ de umidade do material combustível advindo de serapilheira de eucalipto.

Em relação ao tempo de queima, é possível observar na Tabela 3 que houve uma tendência que corrobora, em parte, a hipótese do trabalho, ou seja, quanto maior o volume de água aplicado, maior o tempo de queima. O tratamento testemunha, sem aplicação de água, foi o que apresentou o pior resultado entre os tratamentos, sendo necessários apenas 56 segundos para que o material combustível da área de análise $\left(1 \mathrm{~m}^{2}\right)$ fosse totalmente consumido. Em contrapartida, o tratamento T5 (2,5 L) foi o que demandou maior tempo de contato entre o material combustível com o fogo, para que toda a área avaliada fosse consumida (822 segundos), resultando em um aumento percentual de 1367,86\%.

Dado o fato que, o tempo de queima tem uma relação inversamente proporcional à intensidade de queima, são plausíveis os resultados apresentados na Tabela 4, onde o tratamento testemunha, sem aplicação de água, que teve o menor tempo de queima (Tabela 3), mostrou-se como o de maior intensidade de queima $\left(287,90 \mathrm{kcal} \mathrm{m}^{-1} \mathrm{~s}^{-1}\right)$, sendo cerca de 15 vezes superior ao T5 $(2,5 \mathrm{~L})$ que se caracterizou pela intensidade de $18,78 \mathrm{kcal} \mathrm{m}^{-1} \mathrm{~s}^{-1}$. Outro dado importante em relação à intensidade de queima (Tabela 4), diz respeito à redução percentual promovida pelos tratamentos em relação à testemunha, onde as reduções seguiram uma tendência decrescente: o T5 (2,5 L) reduziu 93,48\% da intensidade de queima; o T4 (2,0 L) reduziu 90,81\%; о T3 (1,5 L), reduziu $87,97 \%$; o T2 (1,0 L), reduziu $85,66 \%$; e o T1 (0,5 L), reduziu $74,99 \%$.

O tratamento 2 com $1 \mathrm{~L} \mathrm{~m}^{-2}$ apresentou intensidade de queima de $41,294 \mathrm{kcal} \mathrm{m}^{-1} \mathrm{~s}^{-1}$, valor próximo ao encontrado por Fiedler et al. (2015) na comparação de eficiência de diferentes retardantes, com calda de $0,5 \mathrm{~L} \mathrm{~m}^{-2}$ e concentração de $0,5 \%$. Os melhores resultados foram respectivamente dos retardantes HMIS 1- 
0-0 DPnb e WD $881 \mathrm{com}$ intensidades de queima de 48,613 $\mathrm{kcal} \mathrm{m}^{-1} \mathrm{~s}^{-1}$ e 54,296 kcal m $\mathrm{m}^{-1}$. Comparando o resultado das duas pesquisas, em situações onde são necessárias ações de prevenção e combate aos incêndios, deve-se realizar uma análise quanto à disponibilidade de recursos e viabilidade econômica, uma vez que a aplicação de $1 \mathrm{~L} \mathrm{~m}^{-2}$ de água equivale ao uso do retardantes HMIS 1-0-0 DPnb e WD 881 com calda de $0,5 \mathrm{~L} \mathrm{~m}^{-2}$ e concentração de $0,5 \%$.

A altura de chamas também apresentou reduções significativas dos tratamentos em relação testemunha (Tabela 4). A altura de chamas apresentou maior amplitude de redução entre os tratamentos, representado por uma redução de $30,23 \%$ no T1 e de $76,74 \%$ nos tratamentos 4 e 5 . Estatisticamente, os melhores resultados obtidos foram com os tratamentos $T 3, T 4$ e $T 5$, variando de 0,47 a $0,33 \mathrm{~m}$ para altura de chama e os tratamentos T4 e T5 respectivamente com valores de 26,45 e $18,78 \mathrm{kcal} \mathrm{m}^{-1} \mathrm{~s}^{-1}$ para intensidade de queima.

Isso mostra que, apesar de existirem técnicas e produtos muito mais eficientes no combate aos incêndios florestais que a água pura (MACHADO FILHO et al., 2012; FIEDLER et al., 2015; CANZIAN et al., 2016; FIEDLER et al., 2020), ela ainda apresenta resultados satisfatórios quando aplicada em volumes mais elevados. No entanto, é sempre importante lembrar que, quanto maior o volume de água aplicado, maior a demanda pelo recurso hídrico, e como explicitado por Canzian et al. (2018) e Fiedler et al. (2020), existe uma escassez conhecida desse recurso nas proximidades das ocorrências.

Para auxiliar na compreensão dos resultados dispostos na Tabela 4, a Figura 3, diz respeito à representação gráfica da regressão linear entre a intensidade de queima e o volume de água aplicado. Nessa figura, o valor de $R^{2}=0,5924$, significa que há $59,24 \%$ de correlação entre as variáveis. Ou seja, $59,24 \%$ da variação de intensidade de queima é causada pelo volume de água aplicado por metro quadrado. Já na Figura 4, é apresentado um $R^{2}$ de 0,899, elucidando um percentual de 89,99\% de correlação entre o volume de água aplicado e a altura das chamas.

Na Figura 5 é possível observar que a relação entre a intensidade de queima e altura de chama é de $80,89 \%$. Ou seja, quanto maior a altura de chama, maior a intensidade de queima. Os tratamentos 4 e 5 foram os que apresentaram melhores resultados, mas não se diferenciaram estatisticamente.

Desta forma, apesar do tratamento 5 apresentar menores valores de altura de chama e intensidade de queima, estatisticamente, o tratamento 4 foi considerado mais viável, pois, além dos resultados serem estatisticamente iguais ao do tratamento 5, o volume de água utilizado foi menor. Assim, o uso correto e bem dimensionado desse recurso representa uma redução de uso de $20 \%$ de água no combate aos incêndios florestais, proporcionando ganhos ambientais e de logística nos combates.

A ação da água sobre o fogo ocorre na redução do calor da combustão e a intensidade de queima representa o quão eficiente o volume de água aplicado pode ser. Seguindo esse conceito, os resultados desta pesquisa demonstraram que quanto maior o volume de água aplicado em uma linha de defesa (aceiro úmido), menores os valores de intensidade de queima. 


\section{CONCLUSÕES}

A hipótese foi corroborada pelos resultados, haja visto que quanto maior o volume de água aplicado, maior o tempo de queima, menor a altura das chamas e a intensidade de queima. A eficiência da água no combate aos incêndios florestais é comprovada em todos os volumes testados, apresentando aumento no tempo de queima e reduções na altura das chamas e na intensidade de queima relativamente significativos.

O tratamento 4 foi o mais adequado e indicado na realização de linha úmida para conter/combater incêndios em florestas de produção tornando-o mais viável ambientalmente e economicamente. Existe uma relação diretamente proporcional entre a altura das chamas e a intensidade de queima e inversamente proporcional entre os volumes de água aplicados e a altura de chama e intensidade de queima. Indica-se aos próximos pesquisadores a análise da eficiência da água no combate aos incêndios florestais em diferentes tipos de material combustível.

\section{REFERÊNCIAS}

ALVARES, C. A.; STAPE, J. L.; SENTELHAS, P. C.. Köppen's climate classification map for Brazil. Meteorologische

Zeitschrift, v.22, n.6, p.711-728, 2013. DOI:

https://doi.org/10.1127/0941-2948/2013/0507

BARBERO, R.; ABATZOGLOU, J. T.; LARKIN, N. K.; KOLDENA, C. A.; STOCKS, B.. Climate change presents increased potential for very large fires in the contiguous United States. International Journal of Wildland Fire, v.26, n.7, p.892-899, 2015. DOI: https://doi.org/10.1071/WF15083

BYRAM, G. M.. Combustion of forest fuels. In: DAVIS, K. P.. Forest fire: control and use. New York: McGraw Hill, 1959. p.77-84.

CANZIAN, W. P.; FIEDLER, N. C.; BRINATE, I. B.; JUVANHOL, R. S.; BIGHI, K. N.. Diferentes concentrações de retardante de fogo em plantios de eucalipto. Nativa, v.4, n.4, p.195-198, 2016. DOI: http://dx.doi.org/10.14583/23187670.v04n04a02

CANZIAN, W. P.; FIEDLER, N. C.; LOUREIRO, E. B.; BERUDE, L. C.. Eficiência do uso da água em métodos de combate a incêndios em florestas plantadas. Nativa, v.6, n.3, p.309312, 2018. DOI: https://doi.org/10.31413/nativa.v6i3.4778

FIEDLER, N. C.; CANZIAN, W. P.; MAFIA, R. G.; RIBEIRO, G. A.; JUNIOR, J. K.. Intensidade de queima de diferentes retardantes de fogo. Revista Árvore, v.39, n.4, p.691-696, 2015. DOI: https://doi.org/10.1590/0100$\underline{67622015000400011}$

FIEDLER, N. C.; LACERDA, G. R.; RAMALHO, A. H. C. R.; BERUDE, L. C.; NEVES, F. P.; RODRIGUES, C. K.. Firefighting combat with fire retardants at different concentrations. Floresta, v.50, n.1, p.1107-1112, 2020. DOI: http://dx.doi.org/10.5380/rf.v50i1.61609

MACHADO FILHO, C.; MARTINS, M. C.; RIBEIRO, G. A.; LIMA, G. S.; CARDOSO, M. T.; TORRES, C. M. M. E.; PINTO, F. B..
Eficiência de um retardante de fogo de longa duração utilizado em incêndios florestais. Ciência Florestal, v.22, n.2, p.365-371, 2012. DOI: https://doi.org/10.1590/S0100$\underline{67622006000600018}$

MARABOTI, V. M.; GONÇALVES, S. B.; CANZIAN, W. P.; FIEDLER, N. C.; MENDONÇA, A. R.. Fire retardantes different efficiency in eucalyptus plantations in the south of Espírito Santo, Brazil. Australian Journal of Basic and Applied Sciences, v.10, n.9, p.24-29, 2016.

RODRÍGUEZ, M. P. R.; SOARES, R. V.; BATISTA, A. C.; TETTO, A. F.; BECERRA, W. M. L.. Comparação entre o perfil dos incêndios florestais de monte alegre, Brasil, e de Pinar Del Rio, Cuba. Floresta, v.43, n.2, p.231-240, 2013. DOI: http://dx.doi.org/10.5380/rf.v43i2.27650

SANT'ANNA, C. M.; FIEDLER, N. C.. Características do Fogo. In: FIEDLER, N. C.; SANT'ANNA, C. M.; RAMALHO, A. H. C.. Incêndios Florestais. Visconde do Rio Branco: Suprema Gráfica, 2020. p.47-54.

SANT'ANNA, C. M.; FIEDLER, N. C.; MINETTE, L. C.. Controle de incêndios florestais. Porto Alegre, 2007.

SOUZA, H. N.; ARAÚJO, T. G.; RIBEIRO, G. A.. Avaliação da eficiência de um gel hidroretentor como retardante de fogo. Árvore, v.36, n.3, p.471-477, 2012. DOI: https://doi.org/10.1590/S0100-67622012000300009

SOUZA, L. J. B.; SOARES, R. V.; BATISTA, A. C.. Modelagem do material combustível superficial em povoamentos de Eucalyptus dunnii, em Três Barras, SC. Cerne, v.9, n.2, p.231245, 2003.

SYPHARD, A. D.; KEELEY, J. E.; PFAFF, A. H.; FERSCHWEILER, K.. Human presence diminishes the importance of climate in driving fire activity across the United States. PNAS, v.114, n.52, p.13750-13755, 2017. DOI: https://doi.org/10.1073/pnas.1713885114

A CBPC - Companhia Brasileira de Produção Científica (CNPJ: 11.221.422/0001-03) detém os direitos materiais desta publicação. Os direitos referem-se à publicação do trabalho em qualquer parte do mundo, incluindo os direitos às renovações, expansões e disseminações da contribuição, bem como outros direitos subsidiários. Todos os trabalhos publicados eletronicamente poderão posteriormente ser publicados em coletâneas impressas sob coordenação da Sustenere Publishing, da Companhia Brasileira de Produção Científica e seus parceiros autorizados. Os (as) autores (as) preservam os direitos autorais, mas não têm permissão para a publicação da contribuição em outro meio, impresso ou digital, em português ou em tradução. 